\title{
Fully undrained cyclic loading simulation on unsaturated soils using an elastoplastic model for unsaturated soils
}

\author{
Veerayut Komolvilas ${ }^{1}$ and Mamoru Kikumoto ${ }^{1, a}$ \\ ${ }^{1}$ Yokohama National University, Tokiwadai 79-5, Hodogaya, Yokohama, Kanagawa 240-8501, Japan
}

\begin{abstract}
Several researchers have reported that Bishop's mean effective stress decreases in unsaturated soils under fully undrained cyclic loading conditions, and unsaturated soils are finally liquefied in a similar manner as saturated soils. This paper presents a series of simulations of such fully undrained cyclic loading on unsaturated soils using an elastoplastic model of the unsaturated soil. This model is formulated using the Bishop's effective stress tensor incorporating the following concepts: the volumetric movement of the state boundary surface containing the normal consolidation line and the critical state line due to the variation in the degree of saturation, a soil water characteristic curve model considering the effect of specific volume and hysteresis, the subloading surface model, and Boyle's law. Comparisons between the simulation results and the experimental ones show that the model agreed well with the unsaturated soil behavior under cyclic loading. Finally, the typical cyclic behavior of unsaturated soils under fully undrained conditions, such as the mechanism of liquefaction of unsaturated soils, the compression behavior, and an increase in the degree of saturation, are described through the proposed simulation results.
\end{abstract}

\section{Introduction}

Soils are often subjected to a cyclic loading under unsaturated conditions in actual fields such as the deformation of embankments and reclaimed grounds during an earthquake. In Japan, the Sanriku-Minami earthquake triggered a landslide in the town of Tsukidate on May 26, 2003. An artificial fill in this disaster area classified as a volcanic sandy soil lost its effective stress under cyclic loading although the degree of saturation is about $70 \%$ [1]. In 2011, the landfills along the northeastern shorelines of the Tokyo Bay liquefied because of the Tohoku earthquake, which caused soil subsidence around an area of $42 \mathrm{~km}^{2}$ [2]. Until now, questions have been raised about the liquefaction potential of unsaturated soils.

Recently, several researchers conducted cyclic shear tests on unsaturated soils to investigate the cyclic shear behavior of the unsaturated soil. Ishihara et al. [3] studied the effects of relative density and the degree of saturation on the undrained behavior of near-saturated sand through multiple series of monotonic and cyclic triaxial tests. Altun and Goktepe [4] conducted a torsional shear test on unsaturated silty clay to explore the small and large strain behavior of unsaturated soils. Unno et al. [1,5] conducted a series of strain-controlled cyclic triaxial tests on the unsaturated sand under fully undrained conditions, namely, unexhausted air and undrained water, to study the general liquefaction state of unsaturated soils. Okamura et al. [6,7] observed the influence of air and suction pressures on the liquefaction resistance of unsaturated soils through a series of cyclic triaxial tests on a fine clean sand and non-plastic silt under fully undrained conditions. Tsukamoto et al. [8] conducted a series of undrained stress-controlled cyclic triaxial tests on the unsaturated sand in order to examine the changes in the cyclic resistance of silty sand with different grain compositions.

All the studies reviewed here support the hypothesis that the mean value of the Bishop's effective stress of the unsaturated soil gradually decreases under fully undrained cyclic loading conditions and the soil is finally liquefied in a similar manner as the saturated soil. The decrease in the effective stress under fully undrained cyclic loading is caused by an increase in pore-air and pore-water pressures, and the liquefaction of the unsaturated soil will occur when both air and water pressures reach the initial value of the total confining pressure [5]. It can be observed that the liquefaction resistance of the unsaturated soil depends on the initial confining pressure; the higher the initial confining pressure, the higher the liquefaction resistance will be $[5$, 6]. The degree of saturation, which has a significant effect on the cyclic behavior of the unsaturated soil, has also been recognized. The cyclic shear strength of the unsaturated soil increases with the decreasing degree of saturation [1, 3-8]. Some results showed that the cyclic stress ratio almost doubled as the degree of saturation decreased from $100 \%$ to $90 \%$ [4, 6]. However, the effect of the degree of saturation on cyclic shear strength will reduce if a low confining pressure is exerted on the unsaturated soil [6]. The compressibility of the

\footnotetext{
a Corresponding author: kikumoto@ynu.ac.jp
} 
unsaturated soil, which depends on the density and soil particle structure, is another important factor that enhances liquefaction. The unsaturated soil with a low relative density (loose) or a highly compressible soil structure may easily lose its effective stress under cyclic loading $[3,5]$. Moreover, the difference in the development of pore-air and pore-water pressures, which causes the liquefaction, varies with the volume change characteristics dependent on the grain size compositions [8]. A change in the volume of the unsaturated soil during undrained cyclic shearing is directly influenced by pore air. According to the hypothesis that the individual soil particles and water are incompressible in comparison with the soil skeleton, a change in the volume of the soil skeleton is assumed to be equal to that of pore air under fully undrained cyclic loading [5]. The pore air absorbs the generated excess pore pressures resulted in a reduction in the pore-air volume $[6,7]$. A reduction in the volume of unsaturated soils during fully undrained cyclic loading causes an increase in the degree of saturation [1, 5]. Suction is a mechanism that affects the cyclic behavior of unsaturated soils [7]. It is usually indicated that suction increases the stiffness of the soil. During cyclic loading, suction decreases because the development of air pressure is less than that of water pressure [1, 5-7]. It should be noted that liquefaction does not occur when suction becomes zero [5].

The main purpose of this paper is to present a series of simulations of fully undrained cyclic loading on unsaturated soils using an elastoplastic constitutive model for unsaturated soils [9]. This model is formulated using the Bishop's effective stress tensor incorporating the following concepts: the volumetric movement of the state boundary surface containing the critical state line due to the variation in the degree of saturation, a soil water characteristic curve model considering the effects of specific volume and hydraulic hysteresis, the subloading surface model, and Boyle's law. Comparisons between the simulation and experimental results show that the model agreed well with the unsaturated soil behavior under cyclic loading. Finally, the typical cyclic behavior of unsaturated soils under fully undrained conditions, such as the mechanism of liquefaction of unsaturated soils, the compression behavior, and an increase in the degree of saturation, are described through the proposed simulation results.

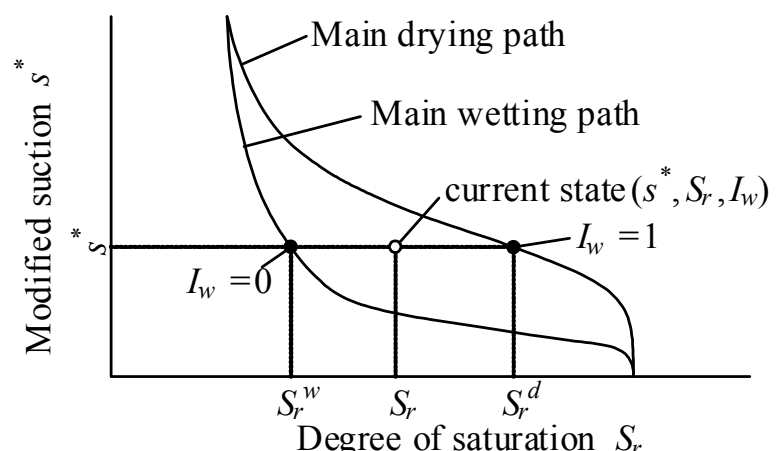

Figure 1. Modeling of water retention curve [9].

\section{Basic concepts}

This section describes the basic concepts applied to formulate a model for unsaturated soils [9], which is used to predict the cyclic behavior of unsaturated soils under fully undrained conditions.

\subsection{The Bishop's effective stress}

In this paper, the effective stress of unsaturated soils is defined based on Bishop's effective stress [10] as shown in equation (1).

$$
\boldsymbol{\sigma}^{\prime \prime}=\boldsymbol{\sigma}-u_{\mathrm{a}} \mathbf{I}+\chi\left(u_{\mathrm{a}}-u_{\mathrm{w}}\right) \mathbf{I}=\boldsymbol{\sigma}^{\text {net }}+S_{\mathrm{r}} s \mathbf{I}
$$

where $\boldsymbol{\sigma}, \boldsymbol{\sigma}^{\text {net }}, u_{\mathrm{a}}, u_{\mathrm{w}}, S_{\mathrm{r}}$, and $s$ represent Cauchy total stress tensor, Cauchy net stress tensor, air pressure, water pressure, degree of saturation, and suction, respectively. $\chi$ is a variable given as a function of $S_{\mathrm{r}}$ and assumed to be equal to $S_{\mathrm{r}}$ in this study for simplicity.

\subsection{Soil water retention curve model considering the effects of density and hydraulic hysteresis}

As described earlier, the degree of saturation, suction, and a volume change affect the cyclic behavior of the unsaturated soil. Therefore, a proper water retention curve model is necessary to formulate an elastoplastic constitutive model for the unsaturated soil. This study uses a modified water retention curve considering the effects of density and hydraulic hysteresis [9].

To consider the effects of density, the van Genuchten model [11] is modified as

$$
S_{\mathrm{r}}=S_{\mathrm{r}_{\min }}+\left(S_{\mathrm{r}_{\max }}-S_{\mathrm{r}_{\min }}\right)\left[1+\left(\alpha s^{*}\right)^{n}\right]^{-m}
$$

where

$$
s^{*}=s\left(\frac{e}{e_{\mathrm{ref}}}\right)^{\xi_{\mathrm{e}}}
$$

where $S_{\mathrm{r}_{\text {min }}}, S_{\mathrm{r}_{\max }}, \alpha, n$, and $m$ are material parameters, $s^{*}$ is the modified suction, $e$ is the void ratio, $e_{\text {ref }}$ is the reference void ratio of saturated, normally consolidated soil under atmospheric pressure, and $\xi_{\mathrm{e}}$ is the parameter controlling the effect of density.

A water retention curve is generally described as the relationship between suction and the degree of saturation dependent on the drying and wetting histories. We define the drying and wetting curves as

$$
S_{\mathrm{r}}^{A}=S_{\mathrm{r}_{\min }}+\left(S_{\mathrm{r}_{\max }}-S_{\mathrm{r}_{\min }}\right)\left[1+\left(\alpha^{A} s^{*}\right)^{n}\right]^{-m}, A=\mathrm{d}, \mathrm{w}
$$

where $\mathrm{d}$ and $\mathrm{w}$ denote the main drying and wetting curves, respectively. Figure 1 illustrates the differences in the main drying and wetting paths which are the highest and lowest boundaries of the degree of saturation. 
The current degree of saturation is the locus of a point between the two main curves represented by $I_{\mathrm{w}}$. $I_{\mathrm{w}}$ is defined as the ratio of interior division of the current state between two reference states on the main curves expressed by equation (5).

$$
I_{\mathrm{w}}=\left(S_{\mathrm{r}}-S_{\mathrm{r}}^{\mathrm{w}}\right)\left(S_{\mathrm{r}}^{\mathrm{d}}-S_{\mathrm{r}}^{\mathrm{w}}\right)^{-1}
$$

Substituting equation (4) in (5) and solving for $S_{\mathrm{r}}$, we obtain

$$
\begin{aligned}
& S_{\mathrm{r}}=I_{\mathrm{w}}\left\{S_{\mathrm{r}_{\text {min }}}+\left(S_{\mathrm{r}_{\text {max }}}-S_{\mathrm{r}_{\text {min }}}\right)\left[1+\left(\alpha^{\mathrm{d}} s^{*}\right)^{n}\right]^{-m}\right\}+ \\
& \left(1-I_{\mathrm{w}}\right)\left\{S_{\mathrm{r}_{\text {min }}}+\left(S_{\mathrm{r}_{\text {max }}}-S_{\mathrm{r}_{\text {min }}}\right)\left[1+\left(\alpha^{\mathrm{w}} s^{*}\right)^{n}\right]^{-m}\right\}
\end{aligned}
$$

We assume that state variable $I_{\mathrm{w}}$ increases monotonically from 0 to 1 with decreasing $S_{\mathrm{r}}$, and vice versa. Thus, an evolution law for $I_{\mathrm{w}}$ can be written as

$$
\mathrm{d} I_{\mathrm{w}}= \begin{cases}-\xi_{\mathrm{w}}\left(1-I_{\mathrm{w}}\right)^{3} \mathrm{~d} S_{\mathrm{r}} & \text { when } \mathrm{d} S_{\mathrm{r}} \leq 0 \\ -\xi_{\mathrm{w}} I_{\mathrm{w}}{ }^{3} \mathrm{~d} S_{\mathrm{r}} & \text { when } \mathrm{d} S_{\mathrm{r}} \geq 0\end{cases}
$$

where $\xi_{\mathrm{w}}$ is the material constant controlling the effect of suction histories.

\subsection{Elastoplastic stress-strain relationship for unsaturated soil}

This section presents an elastoplastic constitutive model for the unsaturated soil [9] formulated by the subloading surface model and the volumetric movement of the state boundary surface containing the critical state line due to the variation in the degree of saturation.

The state boundary surface of the saturated soil, which is the loosest state, can be expressed by

$$
v_{\mathrm{NC}}=\mathrm{N}-\lambda \ln \frac{p^{\prime}}{p_{\mathrm{a}}}
$$

where $v_{\mathrm{NC}}$ is the specific volume of the state boundary surface, $\mathrm{N}$ is the reference specific volume of saturated, normally consolidated soil under atmospheric pressure, $\lambda$ is the compression index, $p^{\prime}$ is the mean effective stress, and $p_{\mathrm{a}}$ is the atmospheric pressure.

As the unsaturated soil shows a relatively high stiffness and retains a larger specific volume than the saturated soil, the state boundary surface is assumed to shift upward (or downward) with the variation in $S_{\mathrm{r}}$ in the direction of the specific volume axis. The effect of $S_{\mathrm{r}}$ on the volumetric movement of the state boundary surface can be represented by

$$
v_{\mathrm{NC}}=\mathrm{N}-\lambda \ln \frac{p^{\prime}}{p_{\mathrm{a}}}+\psi
$$

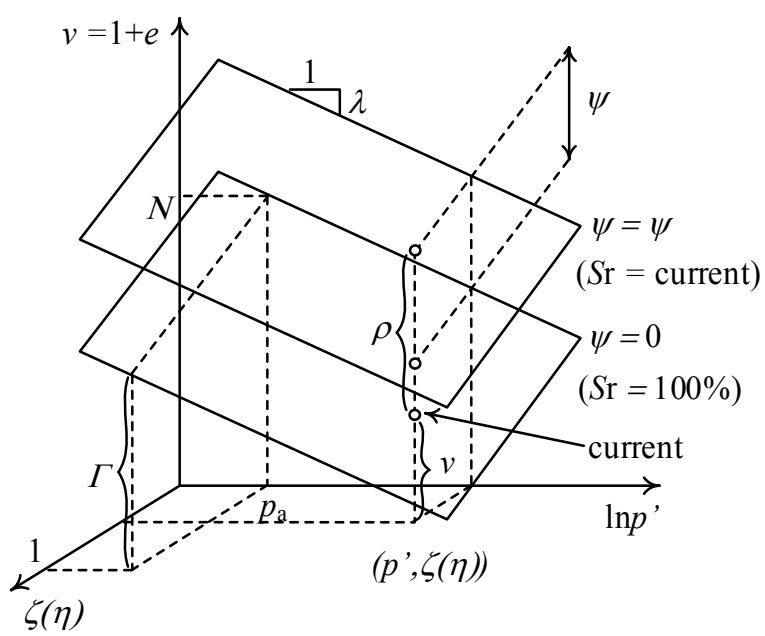

Figure 2. Modeling of the volumetric behavior of the unsaturated soil considering the effects of state variables $\rho$ and $\psi$.

The concept of the state variable $\psi(\geq 0)$ is shown in Figure 2. The variable $\psi$ can be expressed as a function of $S_{\mathrm{r}}$.

$$
\psi=\xi\left(1-S_{\mathrm{r}}\right)
$$

where $\xi$ is the material parameter representing the vertical distance of the state boundary surface for dried and saturated samples in the compression plane.

To consider the behavior of an overconsolidated soil, the subloading surface concept is applied to our model. According to the subloading surface concept [12], a soil exhibits elastoplastic deformation even in an overconsolidated state and then gradually approaches the normal consolidation plane with the increase in the stress level. An arbitrary specific volume can be represented by

$$
v=v_{\mathrm{NC}}-\rho=\mathrm{N}-\lambda \ln \frac{p^{\prime}}{p_{\mathrm{a}}}+\psi-\rho
$$

The concept of state variable $\rho(\geq 0)$ is shown in Figure 2. State variable $\rho$ is the difference between the specific volume of the current state and that of the state on the state boundary surface under the same stress $(p, \zeta(\eta))$. As $\rho$ may decrease with the development of plastic deformation and finally converge to zero, an evolution law of $\rho$ can be represented by

$$
\frac{\mathrm{d} \rho}{v_{0}}=-a \rho|\rho|\left\|\mathrm{d} \varepsilon^{\mathrm{P}}\right\|
$$

where $a$ is a parameter controlling the effect of density.

A monotonic increasing function $\zeta(\eta)$ based on the modified Cam-clay [13] is then applied. We obtain

$$
v=\mathrm{N}-\lambda \ln \frac{p^{\prime}}{p_{\mathrm{a}}}+(\Gamma-\mathrm{N}) \zeta(\eta)+\psi-\rho
$$


Table 1. Parameters for stress-strain characteristics.

\begin{tabular}{ccc}
\hline$\lambda$ & 0.105 & Compression index \\
\hline$\kappa$ & 0.025 & Swelling index \\
\hline$M$ & 1.3 & Stress ratio at critical state \\
\hline$v$ & 0.3 & Poisson ratio \\
\hline $\mathrm{N}$ & 1.80 & Reference specific volume \\
\hline$a$ & 100.0 & $\begin{array}{c}\text { Effect of density and confining } \\
\text { pressure }\end{array}$ \\
\hline$\xi$ & 0.80 & $\begin{array}{c}\text { Effect of } S_{\mathrm{r}} \text { on the position of state } \\
\text { boundary surface }\end{array}$ \\
\hline
\end{tabular}

where $\Gamma$ is the reference specific volume of the saturated soil under atmospheric pressure at a critical state, and $\zeta(\eta)$ is defined as:

$$
\zeta(\eta)=\frac{\ln \left[1+\left(\frac{\eta}{M}\right)^{2}\right]}{\ln 2}
$$

where $\eta$ is the stress ratio, which is equal to $M$ at the critical state.

By substituting $v_{0}, \psi_{0}, \rho_{0}, p_{0}^{\prime}$, and $q=0$ as the initial state in equation (13), we obtain

$$
v_{0}=\mathrm{N}-\lambda \ln \frac{p_{0}^{\prime}}{p_{\mathrm{a}}}+\psi_{0}-\rho_{0}
$$

Total volumetric strain is given by

$$
\varepsilon_{\mathrm{V}}=\frac{-\Delta v}{v_{0}}=\frac{v_{0}-v}{v_{0}}
$$

By substituting equations (13) and (15) in equation (16), we obtain

$$
\varepsilon_{\mathrm{V}}=\frac{1}{v_{0}}\left[\lambda \ln \frac{p^{\prime}}{p_{0}^{\prime}}+(\mathrm{N}-\Gamma) \zeta(\eta)-\left(\psi-\psi_{0}\right)+\left(\rho-\rho_{0}\right)\right]
$$

Elastic volumetric strain can be obtained from a usual elastic relationship as

$$
\varepsilon_{\mathrm{V}}^{\mathrm{e}}=\frac{\kappa}{v_{0}} \lambda \ln \frac{p^{\prime}}{p_{0}^{\prime}}
$$

where $\kappa$ is the swelling index.

Plastic volumetric strain can be determined by subtracting the elastic volumetric strain from the total volumetric strain, which can be expressed as

$$
\varepsilon_{\mathrm{V}}^{\mathrm{P}}=\frac{\lambda-\kappa}{v_{0}} \ln \frac{p^{\prime}}{p_{0}^{\prime}}+\frac{\mathrm{N}-\Gamma}{v_{0}} \zeta(\eta)-\frac{\psi-\psi_{0}}{v_{0}}+\frac{\rho-\rho_{0}}{v_{0}}
$$

\begin{tabular}{|c|c|c|}
\hline$S_{\mathrm{r}_{\max }}$ & 1.0 & \\
\hline$S_{\mathrm{r}_{\mathrm{min}}}$ & 0.20 & \\
\hline$\alpha_{\mathrm{d}}(1 / \mathrm{kPa})$ & 0.04 & Parameters for \\
\hline$\alpha_{\mathrm{w}}(1 / \mathrm{kPa})$ & 2.00 & Van Genuchten model \\
\hline$n$ & 1.67 & \\
\hline$m$ & 0.40 & \\
\hline$\xi_{\mathrm{w}}$ & 34.0 & Influence of suction histories \\
\hline$\xi_{\mathrm{e}}$ & 2.5 & Influence of void ratio \\
\hline$e_{\text {ref }}$ & 0.80 & Reference void ratio \\
\hline
\end{tabular}

From equation (19), yield function can be written as

$$
f=\frac{\lambda-\kappa}{v_{0}} \ln \frac{p^{\prime}}{p_{0}^{\prime}}+\frac{\mathrm{N}-\Gamma}{v_{0}} \zeta(\eta)-\frac{\psi-\psi_{0}}{v_{0}}+\frac{\rho-\rho_{0}}{v_{0}}-\varepsilon_{\mathrm{V}}^{\mathrm{P}}
$$

Table 2. Parameters for water retention curve.

An associated flow is assumed in the model. As the soil exhibits an unlimited distortional strain at the critical state with no change in stress or volume, the derivatives of the yield function with respect to $p^{\prime}$ becomes zero. $(\mathrm{N}-\Gamma)$ is thus equal to $(\lambda-\kappa) \ln 2$ in case equation (14) is applied. Equation (20) can be finally rearranged to

$$
f=\frac{\lambda-\kappa}{v_{0}}\left\{\ln \frac{p^{\prime}}{p_{0}^{\prime}}+\ln \left[1+\left(\frac{\eta}{M}\right)^{2}\right]\right\}-\frac{\psi-\psi_{0}}{v_{0}}+\frac{\rho-\rho_{0}}{v_{0}}-\varepsilon_{\mathrm{V}}^{\mathrm{P}}
$$

The fully undrained condition, namely, unexhausted air and undrained water, is the condition where air and water are unable to drain out of the soil. In other words, the mass of water and air are constant.

In order to simulate the unexhausted air condition, we assume that air is an ideal gas and the temperature is constant. Therefore, Boyle's law, which states that the pressure of a given mass of an ideal gas is inversely proportional to its volume at a constant temperature, can be used as shown in equation (22).

$$
u_{\mathrm{a}} V_{\mathrm{a}}=\text { constant }
$$

where $V_{\mathrm{a}}$ is the volume of air.

A classic equation for solving problems involving threephrase relationships (solid, water, and air) can be used to satisfy the undrained water condition as

$$
w=\frac{e S_{\mathrm{r}}}{G_{\mathrm{s}}}=\text { constant }
$$

where $w, e$, and $G_{\mathrm{s}}$ are the water content, void ratio, and specific gravity of the soil, respectively.

Finally, an elastoplastic model for unsaturated soils [9] can be formulated by applying these basic concepts in order to predict the cyclic behavior of unsaturated soils under fully undrained conditions. 
Table 3. Initial state of cyclic shearing simulation

\begin{tabular}{lcc}
\hline \multicolumn{1}{c}{ Case No. } & $\mathrm{c}-2$ & $\mathrm{c}-3$ \\
\hline Air pressure $(\mathrm{kPa})$ & 6.0 & 14.8 \\
Water pressure $(\mathrm{kPa})$ & 0.0 & 0.0 \\
Suction $(\mathrm{kPa})$ & 6.0 & 14.8 \\
Net stress $(\mathrm{kPa})$ & 18.5 & 19.9 \\
Mean effective stress $(\mathrm{kPa})$ & 23.2 & 30.8 \\
\hline
\end{tabular}

Note mean effective stress is calculated based on the Bishop's effective stress equation, and the pressure is gauge pressure, which excludes atmospheric pressure.

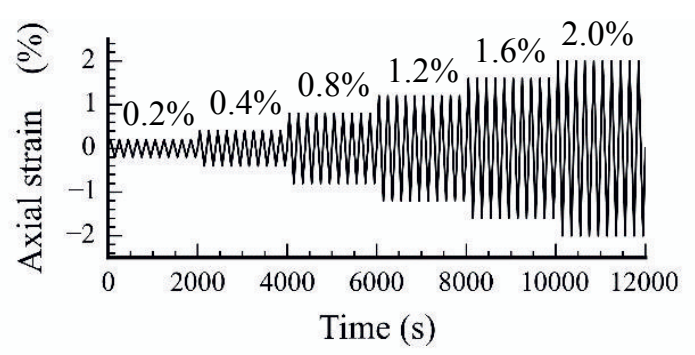

Figure 3. Time history of axial strain during a cyclic shearing process.

\section{Simulations}

A series of simulations of cyclic triaxial tests on unsaturated soils under fully undrained conditions are performed here. The analysis had been carried out using parameters for Tsukidate volcanic sand (non-plastic sand), which has a specific gravity of 2.478 , as shown in Tables 1 and 2 .

Cyclic triaxial tests, conducted by Unno et al. [14], have been performed on two types of unsaturated samples (initial degree of saturation $=78.9 \%$ and $73.5 \%$ with the same initial void ratio of 0.93 ). In the simulation, the initial state of cyclic shearing simulation is first set as shown in Table 3. Cyclic axial strain with a loading frequency of $0.005 \mathrm{~Hz}$ as shown in Figure 3 is then applied to the specimens under the unexhausted air and undrained water conditions at a constant confining pressure. Finally, the simulation results, i.e., the time histories of suction, mean effective stress, air pressure, water pressure, and void ratio, have been obtained as shown in Figures 4 and 5.

Figures 4 and 5 show the comparison between the experimental results for cases c-2 and c-3 conducted by Unno et al. [14] and their corresponding calculations.

According to Figures 4 and 5, the proposed model can precisely describe the cyclic behavior of unsaturated soils under fully undrained cyclic loading conditions. The unsaturated soil lost its effective stress because of the development of pore-air and pore-water pressures and a decrease in suction because the development of air pressure is less than that of water pressure during cyclic shear.

The proposed model can illustrate the fact that liquefaction does not occur when suction becomes zero. Based on the Bishop's effective stress equation, liquefaction of the unsaturated soil will occur when the
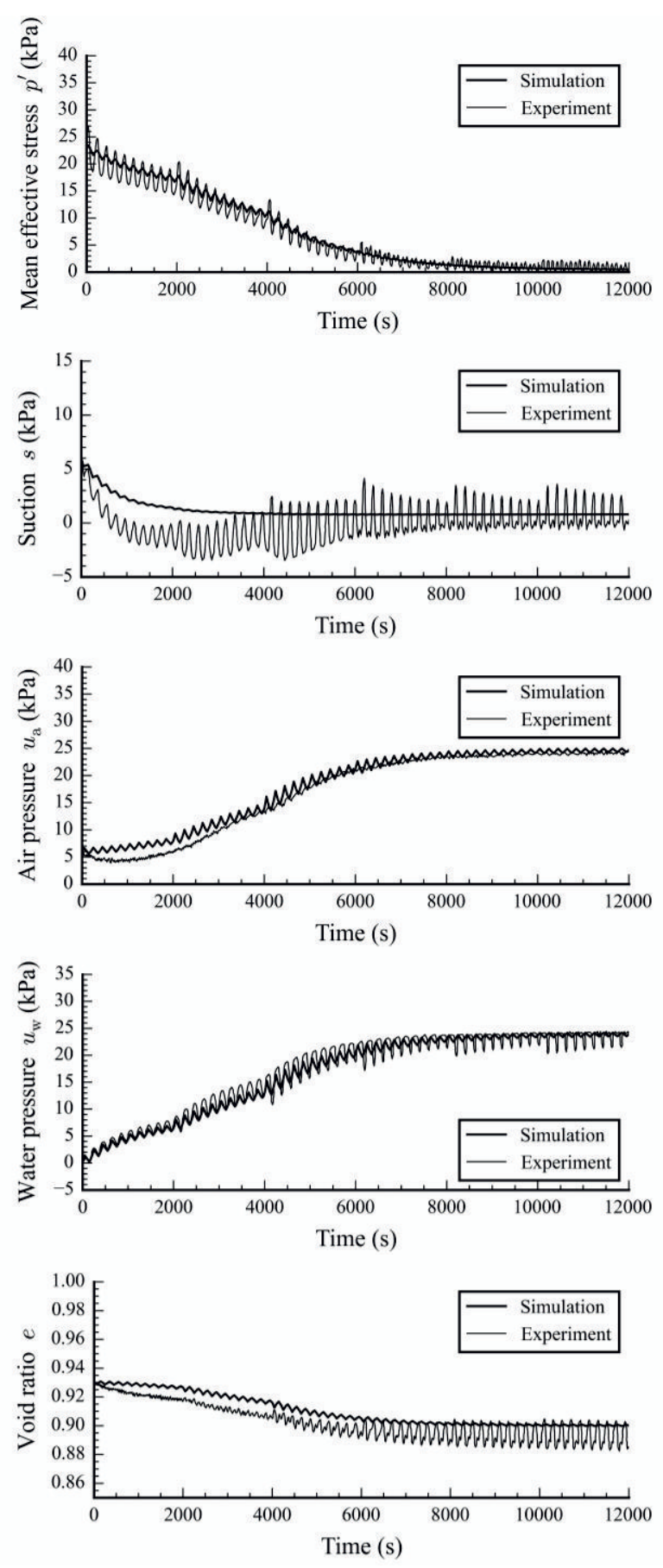

Figure 4. Comparison between the simulation results and the experimental results of case c-2 $\left(S_{\mathrm{r}}=78.9 \%, s=6.0 \mathrm{kPa}\right)$.

suction and the net stress become zero. This situation means that air pressure, water pressure, and total confining pressure must be equal.

Moreover, the proposed model incorporating Boyle's law can capture the compression behavior of unsaturated soils under fully undrained conditions. As air pressure increases during cyclic loading, air volume will automatically decrease following Boyle's law. The magnitude of the decrease in the void ratio was also predicted accurately.

The proposed model for water retention curve can predict the increase in the degree of saturation due to volumetric contraction as shown in Figure 6. 

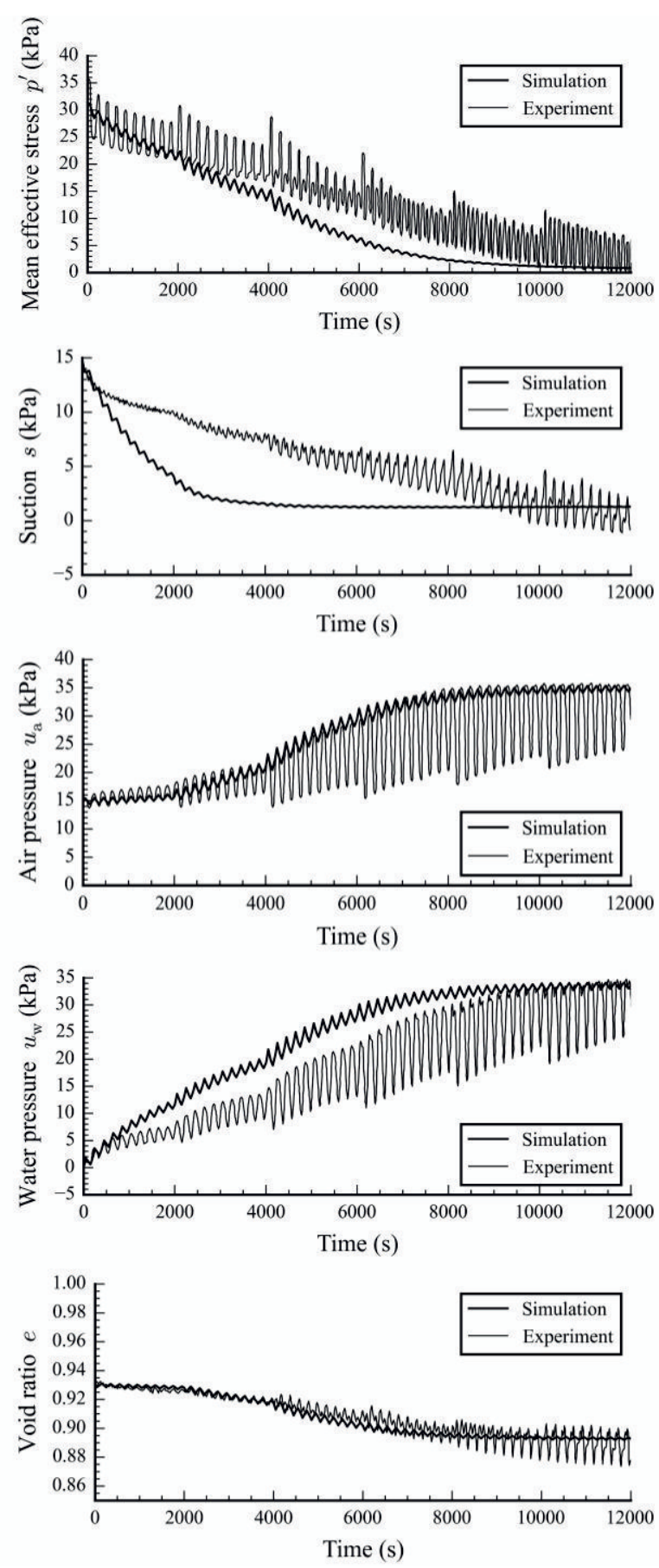

Figure 5. Comparison between the simulation results and the experimental results of case c-3 $\left(S_{\mathrm{r}}=73.5 \%, s=14.8 \mathrm{kPa}\right)$.

\section{Conclusion}

An elastoplastic constitutive model for the unsaturated soil, which is able to predict the cyclic behavior under fully undrained conditions, has been developed.

This model is formulated using the Bishop's effective stress tensor incorporating the following concepts: the volumetric movement of the state boundary surface containing the critical state line due to the variation in the degree of saturation, the soil water characteristic curve model considering the effects of specific volume and hydraulic hysteresis, the subloading surface model, and Boyle's laws.

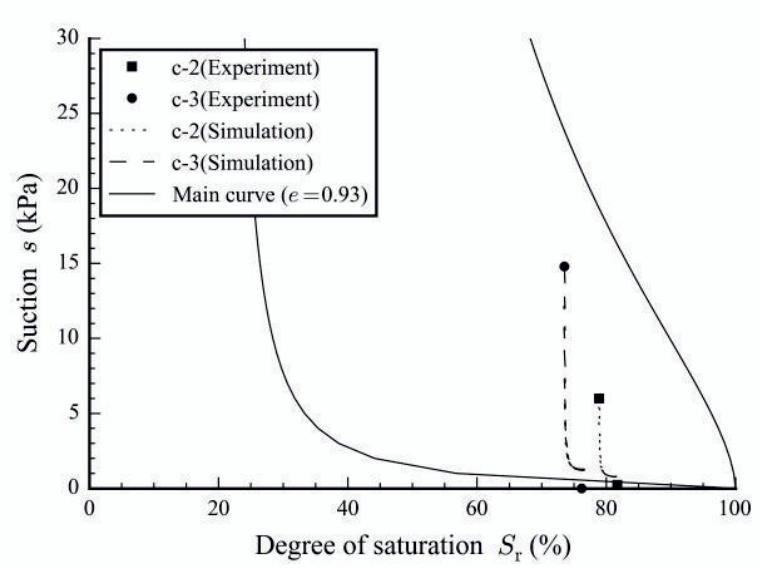

Figure 6. Water retention curve during fully undrained cyclic triaxial test.

The validity of the proposed model is checked through a series of cyclic triaxial tests on unsaturated soils under fully undrained conditions. It is indicated through the simulations that the proposed model properly describes the fully undrained cyclic behavior of unsaturated soils such as liquefaction phenomena, compression behavior, and an increase in the degree of saturation.

\section{References}

1. T. Unno, M. Kazama, N. Sento, R. Uzuoka, The 4th International Conference on Unsaturated Soils, 1133-1144 (2006)

2. K. Konagai, T. Kiyota, S. Suyama, T. Asakura, K. Shibuya, C. Eto, Soil Dyn. Earthq. Eng., 53, 240-253 (2013)

3. K. Ishihara, Y. Tsukamoto, K. Kamada, Cyclic Behavior of Soils and Liquefaction Phenomena, 2739 (2004)

4. S. Altun, A.B. Goktepe, The 4th International Conference on Unsaturated Soils, 497-507 (2006)

5. T. Unno, M. Kazama, R. Uzuoka, N. Sento, Soils. Found., 48, 87-99 (2008)

6. M. Okamura, Y. Soga, Soils. Found., 46, 695-700 (2006)

7. M. Okamura, K. Noguchi, Soils. Found., 49, 221-229 (2009)

8. Y. Tsukamoto, S. Kawabe, J. Matsumoto, S. Hagiwara, Soils. Found., 54, 1094-1103 (2014)

9. M. Kikumoto, H. Kyokawa, T. Nakai, H.M. Shahin, The 5th International Conference on Unsaturated Soils, 849-855 (2010)

10. A.W. Bishop, Teknisk Ukeblad, 39, 859-863 (1959)

11. M. Th. van Genuchten, Soil Sci. Soc. Am. J., 44, 892-898 (1980)

12. K. Hashigushi, M. Ueno, The 9th International Conference on Soil Mechanics and Foundation Engineering, 73-82 (1977)

13. K. Roscoe, J.B. Burland, Engineering Plasticity, 533-609 (1968)

14. T. Unno, R. Uzuoka, N. Sento, M. Kazama, J.S.C.E., 69, 386-403 (2013) 